\section{Engagement politique exemplaire des médecins zurichois}

Durant des mois, la question de la dispensation des médicaments a fait l'objet de débats politiques animés dans le canton de Zurich.

Au centre des débats, la réglementation adoptée par le Grand Conseil zurichois n'autorisant désormais que les médecins de garde et que ceux dont le cabinet est situé à plus de $500 \mathrm{~m}$ d'une pharmacie à distribuer des médicaments. Or, selon une étude géographique, plus de 2000 médecins zurichois auraient été ainsi contraints de renoncer à cette pratique. Seul un très petit nombre d'entre eux auraient eu le droit de distribuer des médicaments pendant les consultations, lors de visites à domicile et en cas d'urgence. Il s'agissait donc de s'élever contre des critères aussi restrictifs, arbitraires et bureaucratiques, raison pour laquelle les médecins zurichois, de concert avec les politiciens, ont vivement combattu ce projet soumis en votation. Avec succès! En effet, approuvé par le parlement et le gouvernement cantonal et soutenu par la plupart des médias zurichois, ce projet n'a pas trouvé grâce devant le peuple.

Or, ce succès n'a été possible que grâce à l'engagement total et déterminé du corps médical zurichois. Fidèles à l'adage "la politique est une affaire de responsabilité", de nombreux médecins ont participé activement à cette campagne. Dans les cabinets médicaux, sur des stands, dans des manifestations et dans les médias, les médecins ont expliqué les conséquences négatives qu'entraînerait une telle réglementation. Le mouvement s'est étendu aux partis politiques. Là aussi, les médecins ont vivement défendu leurs idées lors de débats publics. Tant et si bien que les partis bourgeois ont finalement recommandé le NON et que la gauche a accordé la liberté de vote.

Une première analyse de la votation du 23 septembre montre que la dispensation des médicaments par les médecins est très appréciée par la population, en particulier à la campagne. Selon les communes et l'engagement des médecins, on a enregistré jusqu'à de $80 \%$ de non. Dans les villes de Zurich et de Winterthour, où la propharmacie est encore interdite et donc inconnue, des résultats respectables ont tout de même été atteints.

$A u$ vu du résultat réjouissant de cette votation, toute nouvelle tentative visant à limiter la propharmacie reviendrait à ne pas tenir compte de la volonté populaire. En effet, la population du canton de Zurich a tranché! Les patients, en particulier ceux de la campagne, doivent avoir le choix en matière de distribution des médicaments. Ce résultat réjouissant est notamment dî̀ à l'engagement exemplaire des médecins zurichois qui ont montré à cette occasion comment on pouvait atteindre des objectifs politiques. Je leur adresse toutes mes félicitations!

Dr Sven Bradke Association suisse des médecins avec pharmacie privée (APA) 